\title{
Swimming upstream: the provision of inclusive care to older lesbian, gay and bisexual (LGB) adults in residential and nursing environments in Wales
}

\author{
PAUL WILLIS*, TRACEY MAEGUSUKU-HEWETT*, \\ MICHELE RAITHBY* and PENNY MILES*
}

\begin{abstract}
This paper examines the ways in which older people's residential and nursing homes can constitute heteronormative environments - social spaces in which the same-sex attractions and desires of residents are disregarded in the provision of everyday care. The aim of this discussion is to examine the synergies and differences between older lesbian, gay and bisexual (LGB) adults' expectations for future care home provision and the expectations of care staff and managers in providing residential services to older people with diverse sexual backgrounds. We present qualitative evidence from research into the provision of care environments in Wales. In this paper, we present findings from two cohorts: first, from five focus groups with care and nursing staff and managers; and second, from 29 semi-structured interviews with older LGB adults $\left(5^{\mathrm{O}-} 76\right.$ years) residing in urban and rural locations across Wales. We argue that residential care environments can constitute heterosexualised spaces in which LGB identities are neglected in comparison to the needs and preferences of other residents. To this extent, we discuss how care staff and managers can be more attentive and responsive to the sexual biographies of all residents and argue against the separation of care and sexual orientation in practice.
\end{abstract}

KEY WORDS-lesbian, gay, bisexual, sexuality, identity, residential care, nursing care, care homes, older people.

\section{Introduction}

Sexuality is an integral dimension of health and wellbeing throughout the lifecourse and sexual health is regarded internationally as a holistic 'state of physical, mental and social well-being in relation to sexuality'

* Centre for Innovative Ageing, College of Human and Health Sciences, Swansea University, UK. 
(World Health Organisation 2013). Despite this recognition, older people are often assumed to be lacking sexual desires (Bauer and Geront 1999; Doll 2012). For older people in receipt of residential care, the priority of care needs can overshadow their sexual health needs (Windle and Burholt 20o6). Alongside assumptions of asexuality, older people are frequently presumed to be heterosexual and differences in sexual orientation and identity are sorely neglected. Older adults who identify as lesbian, gay and bisexual (LGB) can experience dual discrimination through the heterosexist assumptions of care providers and through ageist beliefs circulating in LGB communities (Clarke et al. $2010)$.

In this paper, we focus on the perspectives of older LGB adults and the views of care staff and managers providing and administering residential care services in Wales. Our objective is to examine the synergies and differences between older LGB individuals' expectations for future care provision and the expectations of care staff in providing services to older LGB people. To date there has been little discussion of the perspectives of care staff on issues of sexuality and social inclusion despite being key stakeholders in the delivery of services to diverse groups of older people. Examining these two stakeholders' perspectives in parallel provides a mutually informative platform for learning how care practices can encompass the needs of older LGB residents on equal footing with other residents and how care staff and managers can be more attentive to experiences of non-heterosexual ageing. Our research focused on the provision of services to older LGB people in care environments, which included residential and nursing care. The research was conducted from 2011 to 2013 , followed a mixed-methods approach and was led by the question, 'How are the sexual identities and relationships of older LGB residents perceived and supported in residential care environments?' Our argument is twofold. We argue that care environments constitute sexualised spaces in which heterosexual relationships, norms and milestones are routinely privileged over other sexual identities and desires. We propose that for care homes to provide inclusive environments, staff and management alike must have the confidence and communication skills to initiate discussions with all residents about their sexual biographies. This requires being attentive and responsive to older people's sexual histories and life stories. An ethic of care as an alternative framework for understanding care practices can be of benefit here. Before presenting the findings, we outline the background literature and chart the theoretical framework informing the research. Throughout the paper we adhere to the acronym 'LGB' to capture the identity terms nominated by older adults taking part in the research. 


\section{Paul Willis et al.}

\section{Background to the research}

Reviewing literature on older LGB people and ageing highlights three streams of research from Western nations: (a) identifying the health and social care needs of older LGB adults; (b) reporting barriers to equal treatment in residential care environments; and (c) documenting the preferences of older LGB adults for the receipt of future care. Some authors refer to 'LGBT' adults as their research includes transgender people. Our research focused on issues of sexuality and sexual identity and did not examine issues relating to gender identity, however, where we refer to others' research we indicate 'LGBT' populations. Research from Australia and the United States of America (USA) highlight numerous barriers that prevent older LGB people 'coming out' or identifying their sexual identity to other residents and staff in care environments (Barrett 2008; Bauer, Nay and McAuliffe 2009; Heaphy, Yip and Thompson 2004). Hughes' (2009) Australian survey of LGB respondents in Queensland pinpoints a lack of LGBT-specific accommodation and fear of prejudicial treatment from care staff as acute concerns attached to non-heterosexual ageing. Equally, Stein, Beckerman and Sherman (2010: 424) argue that fears of rejection and having to 'go back into the closet' are profound anxieties for lesbian and gay elders in the USA when contemplating residential care. Older lesbian Australians have reported concerns about the lack of representation of their lives in care services' information and marketing (Phillips and Marks 2006). In their appraisal of the literature, Addis et al. (2009) suggest fear of discrimination as a deeply embedded barrier to older LGB adults accessing health, social care and housing services. This finding is echoed in a recent survey from Stonewall (2011), which indicates that LGB adults over 55 years in Great Britain lack confidence in health and social care services.

There is evidence to suggest that LGB adults' fears about future residential care may be a social reality. Attitudinal research indicates that care staff attitudes towards older people's sex lives vary and sexual activity amongst older people continues to be perceived as problematic or risky to self and others (Doll 2012). In the United Kingdom (UK), managers in care environments have been found to be more permissive in attitudes than staff providing direct care, while care staff employed for more than five years report more positive attitudes towards the sexual desires of residents than those with less years of work experience (Bouman, Arcelus and Benbow 2007). Hostility and homophobia towards older LGB adults can also emanate from other residents (Knockel, Quam and Corghan 2011). Findings from Tolley and Ranzijn's (2006) survey of Australian care environments suggest that heteronormative attitudes remain prevalent in residential homes. 
Heteronormativity, the institutionalised assumption of heterosexuality as a normative social marker, can have a twin-fold effect in reinforcing the silence surrounding sexual diversity and increasing the invisibility of nonheterosexual residents (Harrison 20o6). Tolley and Ranzijn (20o6) argue that increased exposure to lesbian and gay residents will help counter-act heteronormative assumptions. Dickey (2013) concurs that exposure to lesbian and gay people will mitigate homophobic attitudes held by nursing staff. However, it is not clear what type and level of exposure to LGB individuals is effective in shifting anti-homosexual attitudes. Here it is important to consider what constitutes knowledge about sexual minority groups as there is a danger in reiterating normative understandings about LGB people's lives. Normative discourses are frequently founded on monolithic views of LGB identity categories that are informed by totalising perceptions of older LGB adults as having shared and fixed needs; this is to the neglect of differences within and between these categories (Cronin et al. 2012).

Perspectives of older LGB (and in some cases transgender) adults in smallscale research indicate a demand for increased choices in the provision of residential care. Lesbian women in Phillips and Marks' (2006) research state a preference for purpose-built retirement homes shared with older women, regardless of sexual identity. In contrast, other older adults have argued for LGBT-specific facilities as more inclusive and safer spaces (Barrett 2008). This preference may be heavily shaped by prior experiences of discrimination from health- and aged-care providers, as reported by older adults in Barrett's (2008) Australian study. The 'Gay and Grey in Dorset' project in south England, conducted from 2003 to 2006, surveyed go older LGB and transgender people (aged $5^{\mathrm{O}-90}$ ) and reported that respondents preferred 'gay-friendly' homes $(38.5 \%)$ or 'gay mixed' facilities as future options for care, while the majority of respondents felt it was important for care professionals to know about their sexuality (Health and Care Development Ltd 2006). Preferences for lesbian and gay-only residential services have likewise been identified in other samples of LGB adults (Hughes 2009; Jackson, Johnson and Roberts 2008; Johnson et al. 2005; Stein, Beckerman and Sherman 2010). This is significant given wider recognition for the 'families of choice' that LGB individuals rely on as opposed to more traditional connections with biological kin (Heaphy and Yip 2003). Older LGB adults are not necessarily in contact with families of birth and adult children cannot be assumed to be an automatic source of support. Accordingly, family members may not be involved in future care planning or be available (or requested) to provide unpaid care. The Stonewall (2011) survey conducted in Great Britain suggests that LGB men and women over 55 are more likely to live alone and less likely to have regular contact with 
biological family compared to heterosexual peers. Likewise, Australian survey research indicates that older gay men over 6o years are more likely to live alone, in comparison to heterosexual men of the same generation, and experience economic disadvantage (Lyons, Pitts and Grierson 2013). Social isolation may be compounded by older people's reported experiences of exclusion and ageism within commercial lesbian and gay venues that are frequently dominated by a youth-centred market (Cronin and King 2012).

Arguably, older LGB adults express similar anxieties about ageing to heterosexual adults, e.g. concerns about declining health, loss of control and diminishing contact with significant others (Hughes 2009; Stein, Beckerman and Sherman 2010). Equally, older LGB adults face unique life challenges that emanate from occupying a marginal status in the social divide between heterosexual and homosexual identities. Older generations of LGB people may be reticent to discuss their sexual history with helping professionals based on past experiences of social and legal discrimination and persecution. Prior to the pre-liberation generation in the 1970 os and the onset of HIV/AIDs in the 1980s, 'coming out' as both a personal and political act was not a valid choice (Barrett 2008; Heaphy and Yip 2003). Within the UK, sexual activity between men was a criminal offence until amended under the Sexual Offences Act 1967 (England and Wales). Homosexuality was listed as a psychiatric disorder in the American Psychiatric Association's Diagnostic Statistical Manual until its removal in 1973 (Fish 2012). Counterbalanced against these adverse factors is the recognition that older LGB adults demonstrate resilience and hope in their future outlook (Lyons, Pitts and Grierson 2013) and articulate strong social support networks or 'social capital' (Cronin and King 2012). Given the recent nature of this socio-legal history, Cronin et al. (2012) stress the importance of biographical approaches to working with older LGB people-this is an empowering mode of capturing their life stories that gives an affirming voice to older adults.

\section{Theoretical framework}

\section{Heterosexuality and heteronormative logic}

Second-wave feminist and sociological authors have critically discussed heterosexuality as a privileged social status that structures everyday relationships in Western societies (Richardson 1996). Heterosexual dominance is sustained through the enmeshment of heterosexuality in everyday life; this is encapsulated in the concept of heteronormativity. Queer theorists define heteronormativity as the cultural saturation of heterosexual norms and 
values in contemporary social and political life (Berlant and Warner 1998; Warner 1993). Queer theory is a cluster of critical theory and philosophy informed by post-structuralist thinking about the relationship between power and language. Queer theorists share concerns for the ways in which dominant ideas about sex, gender and sexuality are sustained through dichotomous thinking and naturalised concepts of self and identity (Brown 2009). This includes critique of the socially defined division between heterosexual and homosexual identities (McPhail 2004) and the limited ways in which sexualities are represented in social discourse. In this context, discourse refers to 'language practices' through which human agents interpret and act upon reality (Healy 2005: 199). Heteronormative discourse rests on the assumption that 'heterosexual experience is synonymous with human experience' (Yep 2002: 167, emphasis in the original). According to Brown (2009), ageing studies has unintentionally silenced the voices of LGBT older people in its body of research, while queer theorists are guilty of not taking into account the dynamics of ageing in their critique of sexual and gender dichotomies.

\section{Care, attentiveness and responsiveness}

Care is a contested concept that encompasses everyday practices of care, critical discussions about who undertakes caring roles, the value accorded to care work, and the requirements and resources that govern who receives care in Western worlds (Barnes 2012). Underpinning definitions of care is the shared understanding that caring involves 'perceiving, interpreting and acting on needs' (Lloyd 20o6: 1178 ) and requires a form of engagement in caring for others (Tronto 1993). Feminist authors have argued that care is a universal human need and social practice; the inter-relatedness of individuals is foregrounded as both a moral and political relationship (Tronto 1993; White and Tronto 2004). Caring activities are best conceptualised as social processes in relationships that follow a moral compass or 'orientation' and are located within broader structural inequalities encompassing divisions in age, socio-economic status and gender (Sevenhuijsen 2000). Caring work is a socially devalued activity that is fulfilled by predominately women, individuals from black and ethnic minority groups, and people from low socio-economic backgrounds (Tronto 1993; Twigg 2000).

Tronto (1993) discusses an 'ethic of care' as a fundamentally moral practice and a relational process in which individuals continually strive to engage in caring for others and be a 'good person'. An ethic of care consists of four elements - attentiveness, responsibility, competence and responsiveness. Here we focus on attentiveness and responsiveness. According to Tronto (1993), attentiveness requires being attuned and receptive to the 
needs of others - to notice others who require care and to avoid actions that do not take into account their concerns. Responsiveness is the capacity of the care-giver to be receptive to and consider the recipient's world-view with the recognition that the other person's experiences and needs differ to the care-giver's self. The two elements are interconnected as 'adequate responsiveness requires attentiveness' (Tronto 1993: 136). Both elements have informed our reading of the reflections of staff and their managers on how best to meet the needs of older LGB residents.

\section{Locating the research in the Welsh context}

As a devolved nation, Wales is rapidly developing its own health and social care agenda which encompasses social care services for older citizens. At the time of writing, the Welsh Government is implementing a separate raft of social services policy under the recently agreed Social Services and Well-being (Wales) Act 2014. Within social policy, the Welsh Government communicates a minority view of LGB populations as a distinct population akin to other socially marginalised groups with social needs that are not fully met or recognised by the broader community. The Welsh Government recognises the differing care needs of older LGB people (Welsh Government 2013), but there is limited discussion on how these needs may diverge from other ageing populations and how they may be met within available, albeit limited, resources. The requirement for public and private care services in Wales to provide anti-discriminatory services to older LGB citizens is reiterated in the UK Equality Act 2010, which recognises both age and sexual orientation as protected characteristics (Section 29, 'Provision of Services, etc.'). This research makes important tracks in expanding on the equality agenda for older people of diverse sexual backgrounds.

\section{Research methods}

Below we report findings from two cohorts: (a) care staff and managers employed in residential and nursing homes across Wales and (b) older adults $\left(5^{\mathrm{O}}-7^{6}\right.$ years) residing in Wales who identified as LGB. We gathered the perspectives of care staff and managers through self-administered questionnaires and focus groups within agencies; in this discussion we concentrate on focus group findings. Three separate groups were facilitated with staff $(\mathrm{N}=14)$ providing direct care to older residents and two focus groups with members of management $(\mathrm{N}=27)$ (private and local authority). The latter groups dovetailed with regional networking events for managers 
and therefore attracted a higher number of participants. Individuals who agreed to participate were employed in homes that were randomly selected from the sampling frame. The sampling frame contained residential and nursing homes for older adults extracted from the Care and Social Services Inspectorate for Wales' 2011 directory online. From four local authorities, residential and nursing homes were randomly selected and $5^{1}$ selected homes received an invitation to participate. Thirty-two $\left(6_{3} \%\right)$ care homes agreed to take part and three of these organisations agreed to their staff participating in focus groups.

Focus groups were co-facilitated by two members of the research team and ran between 45 and go minutes in duration. Topics explored included: previous experiences of providing care to LGB residents; good practice for making residents feel included in the home; barriers to social inclusion; and staff training and policy. Transcripts were analysed line-by-line thematically using the software package NVivo. Core themes were generated through reading on a manifest level for repeated topics and issues, and on a latent level by noting recurring words, expressions and phrases. Core themes were checked by another member of the team for consistency, accuracy and fit with the data.

Older LGB adults were recruited through purposive and snowball sampling. Given the absence of accurate census data about the number of LGB adults living in the UK, it was not possible to seek a representative sample (Price 2011) and we were reliant on self-selection for recruitment. Research advertisements were circulated through regional LGB social groups and networks (e.g. dining clubs or walking groups), older people's advocacy networks and organisations such as Age Cymru. Semi-structured interviews were conducted in 2012 in a location of the participant's choice, typically in their home. Interviews ran between one and three hours with an average length of two hours. Four couples participated in interviews together.

Pugh (2012) discusses the notion of 'care anticipated' to capture the ways in which LGB individuals look to the future and identify priorities and expectations for care informed by their biography and experiences to date. Our interview protocol had a similar future orientation by asking participants to reflect on their expectations for how they would wish to be treated by health and social care staff if they had to enter residential care. Other open-ended questions included hopes and expectations for domiciliary care, experiences of providing or receiving informal care, and points of contact with other LGB adults. Transcripts were thematically coded in NVivo using an interpretative phenomenological framework whereby the focus was on the participant's understanding of their social world, identities and expectations of future care. During the analysis we were mindful of not 
obscuring attention to the heterogeneity of older LGB people's lives - we do not want to convey an artificial image of participants' lives as following uniform trajectories and neglect differences on the basis of other social identities such as age, gender and ability.

\section{The research participants}

Participating care staff and managers were employed in private residential and nursing homes across Wales, encompassing rural and urban areas. Out of 27 managers taking part, 23 were women and over half the group (17) were between the ages of ${ }^{26}{ }^{-} 5^{\circ}$ years. Nineteen participants identified as Christian and the majority of participants (25) were white British; two people were of non-white descent. All managers identified as heterosexual. Nine managers worked in private residential care while others were located in private nursing care (five), local authority residential care (four) or other care settings (four) (five managers did not respond to this item). Out of 14 participating care staff, the majority (nine) were between $3^{0}$

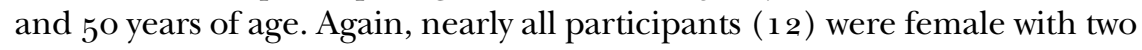
men. Ten staff members were White and four indicated 'Asian/Chinese/ mixed ethnic' background. The majority of staff (13) indicated they were 'heterosexual'; one care worker identified as 'lesbian'. Six participants were currently employed in private nursing homes and eight in private residential care.

The interview sample $(\mathrm{N}=29)$ contained 19 women and 10 men. One person identified as a cross-dressing male; no other participants indicated transgender identities. We recruited more women than men as we had access to a higher number of women's networks that were not available on the same scale for gay and bisexual men in Wales. The majority of participants (23) were between the ages of $5^{\circ}$ and 69 years; six people were between 70 and 76 years. Eighteen participants resided in towns and villages, while 11 participants were located in larger towns and cities. Ten participants identified as Welsh-speakers (fluent and not fluent). Eleven participants were in same-sex relationships, ten were in civil partnerships and one person indicated they were married; seven participants were not in relationships. All participants were white with 26 people of British descent. Over half the group (18) held either degrees or higher degrees, reflecting a high level of educational attainment. Eighteen women identified as lesbian, nine participants as gay and one person as bisexual; one woman described herself as a 'dyke'. We experienced difficulty in accessing older bisexual adults despite attempts to remedy this through snowball sampling and by contacting bisexual communities online. 


\section{Findings}

Reflections on future care: views of older LGB adults

Older LGB participants conveyed in equal amounts their fears and hopes for future care in residential and nursing environments. Participants emphasised the importance of 'equal treatment' to heterosexual residents and accentuated a sense of common humanity by alluding to shared values of respect and dignity. Care homes that treated LGB residents as equal were expected to: (a) welcome partners and friends and uphold the privacy of residents by facilitating private time together; (b) display physical signs of LGB-affirmation such as rainbow signs on entrances and pictures of same-sex couples; and (c) make participants feel comfortable to discuss their personal and sexual lives with other residents and staff. Fundamentally, participants hoped that staff would be mindful that some residents may identify as LGB, be sexually active and have experienced same-sex relationships. However, their hopes did not match their expectations as participants expressed a number of concerns about the receipt of future care. First names stated below are pseudonyms selected by participants.

Looking back, reflecting forward: experiences of discriminatory treatment. A key finding was the importance of LGB histories and the impact that prior experiences had on current or future perceptions of health and social care services. Nearly all participants reported either first-hand experiences or anecdotal cases of discrimination encountered across their life history. The majority of participants had hidden lesbian and gay identities in one or more public arenas to protect themselves from anticipated discrimination, including those who lived a predominantly 'out' life. Homophobic treatment had been experienced within familial, social (e.g. neighbours) and community networks (e.g. Church groups):

My mother found out when I was 13 that I was gay, screamed the house down and made me promise never to do anything about it. So, I didn't. And she died when I was 23 and I just sort of existed... I always thought that I'd never do anything about it [being gay], because I'd promised my mother that I would never do anything about it ... I was 38 coming out ... (Gregory, 53)

Participants had lived through a period of history in which homosexual identities had been classified as a psychiatric disorder with biomedicine. Consequently, some participants had experienced discrimination when accessing health-care services, as evident in Amy's (58) story of seeking support from a psychiatrist:

I remember when I got together with this girl and it was her first same-sex relationship and she was like going to get married in a couple of months after we met and we went 


\section{Paul Willis et al.}

to, well she went to the doctor to tell them all what was going on and he sent her to a psychiatrist in the hospital and I can see the two of us there now, sat in the hospital about 1970 talking to this psychiatrist about feelings we were having and no, it was quite incredible just saying like you shouldn't have those feelings and telling her [partner] to go ahead and get married to this chap and all this, that and the other.

Many of the participants had 'come out' later in life, typically in their mid- to late thirties, and did not feel safe to discuss their sexual attractions and relationships during their youth. This marks a generational shift from recent trends in which young people are more likely to identify as LGB or same-sex attracted during adolescence (Savin-Williams 2005). Annie (61) likened 'coming out' as lesbian during the 1960 s attempting to swim upstream:

... and the minute you try to swim upstream there's somebody there to stop you. It's very difficult just being yourself but it's so important to do it. I mean I ended up in a mental hospital, I hid in a marriage. Back in the sixties they had what was happily called 'queer bashing' in London where I was living, they had queer bashing and gang rapes on lesbians. I was scared, I hid.

In their current lives, some participants continued to experience exclusion and discrimination in their local communities:

Within the [Christian] church that I go to I think there are only two or three people that actually know that I'm gay, two because I actually walked out of a service one time and they wanted to know why. But none of them talk to me about being gay at all, so they basically they don't really want to know...so the gay life that I lead is hidden from them as such because you know it's not the right thing to be doing ... (Gaynor, 62)

Balanced against these oppressive encounters, the majority of participants had experienced fulfilling same-sex relationships, forged new social networks, primarily with friends as 'families of choice', and developed affirmative perceptions of their selves as LGB-identifying individuals.

Given prior experiences of discrimination it was unsurprising that many participants anticipated future negative treatment from residential and nursing staff if having to live in residential care. Concerns ranged from fears of physical and verbal abuse to being separated from partners and significant others. Some participants worried about losing contact with same-sex partners or having restrictions placed on their privacy within the home - this was an acute issue for participants with younger partners in which there was a significant difference in age. Annie (61) discussed her feelings of vulnerability as a lesbian woman:

... to be somewhere where nobody speaks to you is a horrible thought. To be somewhere where somebody was greasing the top step to get rid of you would be worse. I know it's extreme, but that sort of thought is there. To have somebody involved in personal care who didn't like you because of your orientation, that doesn't sound good either... You hear about people in care homes who are 
mistreated ... Are they going to be worse towards you? Scary - the way you are going to be treated is scary, it scares me.

While speculative, these concerns were genuinely felt for older adults when reflecting on 'care anticipated' and more accurately reflected 'care dreaded'.

Heterosexual norms and assumptions embedded in future care. Both men and women expressed their concerns about the prevailing assumption of heterosexuality, in particular how this assumption may shape future care received. Heterosexual milestones such as marriage and the birth of children were recurring dimensions of their stories. Nearly half the sample (14) had entered into marriages prior to 'coming out' as LGB; both men and women described how they had shared their lives with opposite-sex partners and in some cases parented children together. Former marriages were described in multiple ways - to hide homosexual identities and desires, to satisfy the heteronormative expectations of others such as family members, and to dispel or resist same-sex attractions. During his thirties, Meirion (73) believed he had been 'cured' of same-sex attractions: 'I didn't get married until I was 35. Ironically I was in love with [wife's name], and thought, I'm cured. I realised very quickly I wasn't...' Equally, participants did not express regrets about relationships shared with their children or about their role as parents. In the main, marriage was framed as a separate life chapter from their present lives and many participants resented the prospect of being presumed to be straight by care staff:

I don't want people making jokes about boyfriends, you know, and 'what did your husband do dear?', yes, I suppose that's what it's about really, just the same as now when I have a conversation with somebody I don't want them assuming that I'm straight ... and it's the same for when I'm old and needy. (Mary, 61)

Similarly, several participants relayed their anxieties about having to go 'back into the closet' if they moved into a care home - having to make invisible aspects of their sexual lives and histories they had grown accustomed to sharing with others:

I suppose I can't imagine being in a place where everybody around you would not know that you had spent all of your life as a lesbian, I mean that would be, there is no point in living, that would be the worst thing for me if you had to be completely in the closet with nobody knowing about you and you couldn't talk about your life ... (Sarah, 59)

Alongside worries about declining health and mobility, several women relayed their dread of losing control over their personal dress and appearance while in the receipt of care. These anxieties stemmed from a deeper concern about having conventional gender roles and feminine attributes enforced upon them by care staff without their consent or control. 


\section{Paul Willis et al.}

This included being dressed in skirts or other feminine apparel, sharing living spaces with male residents or having intimate contact with male carers. This was a source of heightened anxiety for some lesbian and gay women who had very little contact with men and who relied on primarily womenonly networks within their local communities:

... and again I think it is about being a woman, somebody of the same sex, I wouldn't want a man coming in to give care ... I'm sure that's the same with a lot of women, it's not just a lesbian thing, it's about just feeling more secure with another woman as opposed to a man, that's important... (Eleanor, 54)

When considering the number of concerns expressed about future residential care, it is not surprising that over half the sample ( 13 women, two men) indicated their preference to live in LGB-specific facilities. These were imagined environments in which heterosexual norms and assumptions would not feature in the delivery of care and participants could anticipate feeling safe and valued as LGB adults. This was more common among female participants who had established women-only networks for mutual support. Some women indicated their preference for living in gender-specific facilities: 'my ideal in terms of care would be to be in a sort of sheltered accommodation that was just for lesbians . . . because I wouldn't particularly want men around, to be honest, gay men or straight men' (Eleanor, 54). Historically, LGB older people have not relied on traditional family networks and have developed alternative support networks as 'families of choice' (Brown 2009). The future preference of LGB-specific facilities or single-sex facilities reflects this social reality in which some older LGB adults seek care environments in which anxieties about contact with partners, lovers and friends are potentially negated.

\section{Reflecting on current practice: views of care staff and managers}

'Not on this floor': missing identities in care environments. When recounting their experiences of providing care to older adults, staff and managers described sexualised environments in which staff and residents were regularly engaged in intimately charged interactions. This can be summarised across four domains: (a) witnessing the sexual activities of residents, e.g. masturbation; (b) observing flirtatious behaviour and sexualised banter between residents of the opposite sex; (c) managing physical contact between residents and observing residents form new romantic relationships, and $(\mathrm{d})$ receiving sexual contact from residents, e.g. being groped or pinched. The following comments encapsulate these domains:

... I have walked past someone's room and they've got porn on, so all I did was I just knocked his door, I said, 'you know, there's no problem with you having it on but I'll just shut your door' ... (Care staff) 
... staff phone me, I was in the office, buzzed me through and said, 'So and so's playing with himself in the lounge,' I said, 'Okay,' we went in and said you know, 'Don't mind what you're doing but can you go to your room and do that 'cos some people don't want to see you do that'. (Manager)

How many times have we had our bums pinched or you've had your boobs groped? (Care staff)

These interactions were familiar dynamics to both care staff and managers. In contrast, staff and managers struggled to articulate knowledge of residents who identified as LGB or had been in same-sex relationships. The absence of discussion about LGB lives and identities stood in stark contrast to discussions about residents' marital partners, the ways in which married heterosexual couples were accommodated, e.g. provision of adjoining rooms, and the inclusion of heterosexual partners and children as visitors. LGB identities and histories were equally absent from staff development activities. No one recalled receiving training about issues of sexuality, identity and equality. Some participants had undertaken training on managing sexualised behaviours exhibited by residents with dementia-in this context, residents' sexual desires was framed as problematic and risky.

One staff member described the absence of LGB residents as "not on this floor'. Another person indicated that this information was not included in residents' care plans when older people were transitioning into the home, making it difficult to establish this information when building rapport with new residents. Furthermore, staff and managers conveyed a limited understanding about sexual identity, LGB symbols and history, and in some instances struggled to speak the words 'lesbian/gay/ bisexual' aloud:

But no, we've never really discussed it actually but we've discussed ethnic [residents], you know, black, coloured, but we've never discussed, it's really strange but I think it's all up to the same thing it's, you know, when you're nursing someone you tend to their needs or what's good for them, don't you rather than ... [statement unfinished] (Care staff)

The above statement alludes to a resident's sexual identity as separate and subsidiary to their care needs. The separation of health care from sexual orientation was further emphasised by another staff member: '... and they're normal people and there is nothing wrong with them but when you're in a nursing home it's, you really have to think about their illnesses and why it's happening, you know...' Older staff communicated some awareness of historical discrimination and indicated their understanding that the socio-legal status of LGB people in the UK had improved over the last five decades. Some staff discussed discrimination in the 
past tense and implied it was no longer a problem in the contemporary world:

And its [homosexual identities] been accepted better now than it did years ago so it's not as bad as it was years ago... It's not a problem is it? It's not a problem anyway but you just wouldn't say it when we were young would you? It was a, not a bad word, but you just didn't say it and I think that's because it was hidden. (Care staff)

In contrast, participants were no strangers to lesbian and gay lives as numerous staff members had extended family members who identified as LGB. Several participants communicated their knowledge of other lesbian and gay employees in which the identities and relationships of co-workers was common knowledge amongst teams. While lesbian and gay staff were familiar figures in several participating homes, their sexual identity was not usually broached with residents. The exception was one home in which a member of staff was engaged to his partner; the manager emphasised the positive outcomes of this pending celebration for staff and residents alike:

They're getting married and that has really opened up the home because they're a fab couple ... and like some of the residents are really fine about it, others you don't mention it in front of them. Because they've got objections to it so you just don't speak in front of them about them, other people, other residents want to really be involved in it. (Manager)

This is an exceptional story that signifies how the inclusion of gay identities can be collectively valued by both staff and residents and that care environments are not exclusively heterosexualised spaces. Conversely, it also touches on the tensions present between residents around issues of sexual difference and diversity - this subject remains 'unmentionable' in the presence of some residents.

Different but same: responding to LGB difference. For care staff and managers equality primarily equated with sameness-treating older LGB adults as having the same needs and wishes as heterosexual residents. Emphasis was given to the provision of equal care regardless of sexual identity and social background: 'Well I'd just be normal, isn't it, you just, everyone's the same so you're just being the same with everyone' (Care staff). This was to the detriment of recognising individual differences in sexual identity and biography. In contrast, notions of equality were discussed by older LGB adults as receiving equal treatment to heterosexual residents which encompassed respect and recognition for individual dignity, identity and the role of significant others, including same-sex partners. Interview participants discussed respect and privacy as intertwined with the recognition of LGB identities; care staff and managers discussed these 
principles predominantly in reference to other residents' wellbeing. Examples included seeking to prevent emotional distress to other residents or wishing to shield the discriminatory views of other residents, even when these views may cause potential offence.

To initiate discussions about sexual identity ran the risk of causing offence to the individual resident or infringing privacy; LGB identities were relegated to the private sphere and therefore not for public discussion. In one isolated case, a manager raised her concern about the rights of other residents to express their personal views, regardless of whether their views could be experienced as homophobic or racist:

You can't make people behave themselves, it's their home they're living in, and they have to be able to say what they want to say. And I think we have to sort of pick up the pieces and support the person they've upset, maybe. (Manager)

While supporting the offended party demonstrates willingness to follow-up, it does not clarify how the derogatory comments of the other party will be addressed. From this standpoint, older residents are perceived as 'stuck in their ways' - holding fixed beliefs and unwilling to rethink how their views may impact on others. Furthermore, the right of LGB residents to feel safe in their home environment is superseded by the right of other residents to express their views freely.

Care was frequently framed as disconnected to sexuality. Sexual orientation was located as an extraneous factor that did not constitute providing good care to others:

You are nursing these people and we're all human, maybe gentlemen or lady, you know its part of, you sort of, you don't think about it actually, you know it's just part of everyday life when you're nursing someone. Yeah, you know you are looking after people's needs and what's best for them and what would help them rather than judge them for what they are. (Care staff)

Throughout group discussions, references were made to the importance ofindividualised care. This included discussions about 'person-centred care' as a cited model of good practice in nursing care. Nolan et al. (2004: 46) argues that person-centred care is an 'oft quoted but ill-defined concept' in gerontological nursing that promotes attention to the unique wishes and preferences of older residents as autonomous individuals and upholds respect for individuality and personhood. One manger discussed this approach in the context of maintaining daily routines important to individual residents:

You know they're [gay residents] going to be the same as everybody else. They're going to say, 'Well I don't like gravy on my dinner. I like two sugars in my coffee.' Surely they're not going to come in here and go, 'Well I'm gay. Now then what are you going to do about it?' (Manager) 


\section{Paul Willis et al.}

While decisions about dietary habits or bedtime are important aspects of individual routines, the sexual biography of a resident is an equally significant source of knowledge about self and others. This information formulates a critical part of providing a holistic person-centred service that takes into account multiple facets of the individual's biography. In our research discussions about person-centred care did not encompass sex, sexual identity and biography.

Moving forward: the case for change. While seeking to locate sexual orientation as separate to the provision of care, staff and managers equally relayed their desire to be 'doing more' to ensure the inclusion of LGB residents. There was an open acknowledgement of the case for change and the need to enhance knowledge and understanding about LGB lives. Participants were eager for more information about LGB lives and increased knowledge about ageing and sexual functioning in later life:

Yeah, I think we've got an awful long way to go on meeting people's sexuality needs in care homes, full stop. That means man-woman relationships as well, you know, we've got to get it all right. (Manager)

Some managers felt 'bereft of information' and 'lacking in expertise'. Managers wanted to learn from care staff in other organisations about their experiences of working with LGB residents and they sought guidelines on how to 'work with' LGB residents as a minority group.

Strong leadership was perceived as fundamental to driving forward change in the culture of care environments. From this position, it was felt that training needed to be management-led to make sure all staff recognised its value and for professional development to be part of the philosophy of the home:

You should be open and you should be accepting to other people's sexual orientation, because if the leader in herself or himself is not very open or quite negative to that respect, and what would you expect the staff will do, follow suit isn't it? (Manager)

Cultural change in homes also entailed communicating to visitors and new residents the values of the organisation. While the effectiveness of written polices was given little credence, some managers suggested including an assertion about LGB residents in the agency's statement of purpose:

... Within your statement of purpose maybe, you know, so that people looking to come into your home, you give them a statement of purpose to look at... that's another way of promoting your nursing home to say, 'Look, we're quite open and we'll be looking to take anyone, treat them as an individual, but there could be someone in here that's gay and you know if you're not as happy with that then look elsewhere'. (Manager) 
The intention behind this statement is to communicate to potential residents and significant others that this care home is an inclusive environment in which diverse groups of older people are equally valued. It is a simple but powerful statement that has the potential to trouble heteronormative assumptions.

\section{Discussion}

In this paper we set out to examine the expectations of older LGB individuals for future residential care in parallel to the current experiences of care staff and managers in providing care to residents, inclusive of older LGB adults. This discussion makes a significant contribution to the field of sexuality and ageing by bringing these two perspectives together in which there is currently little research into the views and practices of care staff providing support to older LGB adults. As such, there are a number of key points to be gleaned from the findings that bear implications for improving care practice both locally and internationally.

Within the accounts of care staff and managers, care environments are depicted as sexualised spaces in which staff and residents are frequently engaged in intimate interactions across a number of domains. These descriptions of sexualised environments trouble dominant notions of older people as sexually inactive and clearly indicate that residents' sexual lives are not left at the front door of care homes (Doll 2012). Furthermore, these interactions constitute care environments as hetero-sexualised spaces in which the discussion and expression of non-heterosexual identities and sexual practices is glaringly absent. Within heterosexualised spaces, older LGB residents are not awarded equal status as other residents and fundamental elements of their biography are perceived as extraneous to the provision of care. Non-normative sexual identities are located as separate or irrelevant to providing care to others; in this context care is framed as a sexually neutral practice. Consequently, heterosexual norms and assumptions remain intact and unquestioned while LGB identities are largely invisible. This dominant arrangement is further sustained through a discourse of 'equal-same treatment'. Within this discourse lies an assumption that it is the responsibility of LGB residents (and their significant others) to initiate discussions about their sexual lives and to correct the presumption of heterosexuality. This does not take into account the socio-legal history of social exclusion and discrimination, both at an institutional and individual level, experienced by older LGB adults in the UK and more widely in other Western nations.

Older LGB adults' experiences of homophobia across the lifecourse have been documented in the literature (Addis et al. 2009; Fredriksen-Goldsen 
and Muraco 2010) and re-articulated here as a foreground to participants' concerns for future care provision. Care staff and providers need an understanding of discrimination endured by LGB individuals across their lifecourse and how this impacts on LGB individuals' present and future interactions with health and social care professionals. In Heaphy, Yip and Thompson's (2004: 892) study of non-heterosexual ageing in the UK, the majority of older participants spoke of receiving future care in residential settings as 'highly undesirable'. Older adults participating in our research echo this sentiment as they conveyed their fears about discriminatory treatment or experiencing separation from significant others. Our participants are not unique in this respect and their preferences for gender-specific or LGB-exclusive facilities mirrors the reported preferences of other older LGB adults across other nations, including the UK, USA and Australia (Health and Care Development Ltd 2006; Hughes 20o9; Jackson, Johnson and Roberts 2008; Johnson et al. 2005; Stein, Beckerman and Sherman 2010). Indeed, at the time of writing this paper, housing provision targeted towards older LGB adults is already established internationally. For example, LGBT-specific retirement homes are operating in other European nations, including France and Spain, and in some US states (BBC News 2014). An inherent expectation within this preferred arrangement is that concerns attached to non-heterosexual ageing and discrimination will be abated. Conversely, a demand for separate care environments runs against the recent implementation of the Equality Act 2010 in England and Wales that requires all service providers, public and private, to supply a non-discriminatory service.

\section{Dismantling heteronormative attitudes}

In their Australian study, Tolley and Ranzijn (2006) assert that exposure to lesbian and gay lives will assist in dismantling heteronormative attitudes among care staff. In our research, many participating staff members had already experienced some degree of exposure to lesbian and gay lives through other employees or via personal networks. In addition, the increasing representation of LGB lives and relationships through popular media brings another layer of cultural exposure. An alternative question to ask is how attentive are staff members to facets of LGB adults' biographies when they do have contact with LGB individuals, including older adults. Within an ethic of care, White and Tronto (2004) frame care as a public and a political matter - the need for and the provision of care is a universal principle and a 'public activity' that involves all members of society. It is difficult to recognise the care needs of older LGB people as a shared responsibility when organisations work to relegate socio-sexual dimensions 
of their lives to the private sphere; LGB identities are cloaked in silence or represented as unspeakable topics. Care staff communicate their motivation to be more attentive and responsive to the wishes of LGB residents, however, they lack the communication tools and confidence to be attuned to differences in sexual identity and life history. Moreover, the dominant discourse of 'equal-same treatment' may blinker employees and managers from being more attentive to the sexual histories of LGB residents in their care.

Older LGB adults need to feel trust and confidence in service providers before sharing aspects of their sexual biography. This requires staff and managers alike to have the confidence to initiate ongoing discussions with residents about their sexual histories. Initiating these conversations is an equally important aspect of providing person-centred care to older adults. Care staff and management need to stay attentive to non-normative sexual lives and be mindful of the world-views of individual residents. Respecting individual personhood involves recognising preferences and wishes such as choice of clothing, gender of carers, and language used to describe identities and relationships. Having to live in mixed-gender environments was an acute concern for women participants in which significant periods of their past and present lives had revolved around relationships with other women. From this position, the gender of residents matters equally alongside sexuality.

Gaining the trust of LGB residents also entails a willingness to be responsive to instances in which their safety and wellbeing may be comprised by the actions of others, staff or visitors. Being prepared to challenge the oppressive views expressed by residents is a mandatory requirement, particularly when these expressions compromise the rights of other residents to feel safe in their home environments. This requires a recognition that older residents can, and may be receptive to, rethinking their beliefs when their views may cause emotional injury to others. In this regard, challenging oppressive exchanges is part of providing inclusive care-care for the emotional wellbeing and human rights of residents.

\section{Limitations and future directions}

The present research is not without its limitations. Missing from the interview sample are the voices of older adults who identify as bisexual and the views of older people from ethnically diverse backgrounds. These gaps result from an inherent difficulty in relying on self-selected sampling. In parallel, the views of black and ethnic minority staff are under-represented in discussions with staff and managers. This is contrary to our observations of ethnically diverse staff groups employed within participating care homes. It is hard to ascertain if their reluctance to participate is based on differences in language, 
religious beliefs or ethnicity, or whether these employees were avoided by managers acting as 'gatekeepers' when approaching staff to participate. We are reluctant to make generalisations about employees from a wide range of national backgrounds without tangible evidence as to why they did not participate. The present research did not include the voices of residents currently receiving care. We are mindful that residents constitute important stakeholders and future research should seek to gather their perspectives on contact with LGB residents and staff. Finally, our research did not focus on issues of gender identity; this is a topic that warrants investigation, in particular how transgender older people are supported to maintain daily routines of bodily care and self-presentation in residential and nursing services.

\section{Implications for developing inclusive care}

At the heart of our research is a commitment to enhancing recognition of the human rights of older LGB people and advocating for greater inclusion of their lives and identities in care environments, both locally and internationally. In parallel to Knockel, Quam and Corghan's (2011) findings, care staff and managers in our research were eager for training in this area and receptive to expanding their knowledge of LGB histories. We concur that all staff and their managers require enhanced training in this field. However, further consideration needs to be given to the type of training received. We are reluctant to advocate a 'how-to-work-with-LGBadults' approach that implies that older LGB adults have distinct health and social care needs as a separate cohort. This approach potentially sustains social divisions between heterosexual and homosexual identities and overlooks diversity within and between LGB lives. Internationally there are a number of training programmes in existence with a 'cultural competence' orientation that focus on extending knowledge about the lives of older LGB adults (e.g. SAGE's resource 'No Need to Fear, No Need to hide' in the USA, and from Canada, Toronto's Long-term Care Homes \& Services 'Diversity Our Strength'). As an alternative approach, there is scope for training on increasing interpersonal skills and attentiveness to all residents' sexual biographies, including LGB lives. These are sensitive topics to discuss with older people whose capacities may be limited because of declines in mental and physical health. Nonetheless, these are important conversations to initiate from early contact with residents transitioning into care environments or, where limited capacity does not permit, with carers and significant others who have an integral role in care-giving alongside employed staff. Externally, there is an instrumental role for health and social care inspectorates as regulatory agencies to ensure that care staff 
receive ongoing training in this area. These agencies are ideally situated to assist care homes with assessing and monitoring how they can avoid the presumption of heterosexuality in the delivery of care and how to provide inclusive environments from initial contact onwards.

\section{Conclusion}

While care environments in Wales, and indeed in other nations, have further work to undertake in developing more sexually inclusive environments, our research has highlighted the willingness of staff and managers to change current practices and the motivation to learn from other agencies and providers. We suggest that an essential element to taking forward this change agenda is the requirement to integrate recognition of residents' sexual biographies with current practice concepts of individualised and personcentred care. An ethic of care, in particular elements of attentiveness and responsiveness, can help bridge this theory-practice gap and enhance staff and managers' capacity to be more receptive and protective of the sexual histories and wellbeing of all residents in their care. While the research findings are specific to Wales, these core messages are transferable to care home providers in other Western nations that seek to enhance employees' understanding of non-heterosexual ageing and divergences in sexual histories, life events and social identities. This is acutely so for nations sharing a similar modern history of homosexual persecution and criminalisation and whose public bodies are currently seeking to remedy past harms through a more just recognition of older LGB citizens' lives and civil rights in policy and practice.

\section{Acknowledgements}

This research was funded by the National Institute for Social Care and Health Research (NISCHR), Welsh Government. The project received ethical approval from the NHS Wales National Research Ethics Service (reference 11/WA/o217), local R\&D approval from Abertawe Bro Morgannwg, Cardiff and Vale and Betsi Cadwaladr University Health Boards, and University ethics approval.

\section{References}

Addis, S., Davies, M., Greene, G., MacBride-Stewart, S. and Shepherd, M. 2009. The health, social care and housing needs of lesbian, gay, bisexual and transgender older people: a review of the literature. Health and Social Care in the Community, $17,6,647-58$.

BBC News 2014. The Growth of Gay Retirement Homes. British Broadcasting Corporation. Available online at http://www.bbc.co.uk/news/magazine-26554710. 


\section{Paul Willis et al.}

Barnes, M. 2012. Care in Everyday Life: An Ethic of Care in Practice. Policy Press, Bristol, UK.

Barrett, C. 2008. My People: A Project Exploring the Experiences of Gay, Lesbian, Bisexual, Transgender and Intersex Seniors in Aged-care Services. Available online at http://www. matrixguildvic.org.au/MyPeopleReport20o8.pdf [Accessed 16 October 2009].

Bauer, M. and Geront, M. 1999. The use of humour in addressing the sexuality of elderly nursing home residents. Sexuality and Disability, 17, 2, 147-55.

Bauer, M., Nay, R. and McAuliffe, L. 2009. Catering to love, sex and intimacy in residential aged care: what information is provided to consumers? Sexuality and Disability, 27, 1, 3-9.

Berlant, L. and Warner, M. 1998. Sex in public. Critical Inquiry, 24, 2, 547-66.

Bouman, W. P., Arcelus, J. and Benbow, S. M. 2007. Nottingham Study of Sexuality and Ageing (NoSSA II). Attitudes of care staff regarding sexuality and residents: a study in residential and nursing homes. Sexual and Relationship Therapy, 22, 1, 45-61.

Brown, M. T. 2009. LGBT ageing and rhetorical silence. Sexuality Research and Social Policy, 6, $4,65^{-7} 8$.

Clarke, V., Ellis, S.J., Peel, E. and Riggs, D. 2010. Lesbian, Gay, Bisexual, Trans and Queer Psychology: An Introduction. Cambridge University Press, Cambridge.

Cronin, A. and King, A. 2012 . Only connect? Older lesbian, gay and bisexual (LGB) adults and social capital. Ageing Eं Society, 34, 2, 258-79.

Cronin, A., Ward, R., Pugh, S., King, A. and Price, E. 2012. Categories and their consequences: understanding and supporting the care relationships of older lesbian, gay and bisexual people. In Ward, R., Rivers, I. and Sutherland, M. (eds), Lesbian, Gay, Bisexual and Transgender Ageing: Biographical Approaches for Inclusive Care and Support. Jessica Kingsley Publishers, London, 102-13.

Dickey, G. 2013. Survey of homophobia: views on sexual orientation from certified nurse assistants who work in long-term care. Research on Ageing, 35, 5, 563-70.

Doll, G. A. 201 2. Sexuality and Long-term Care: Understanding and Supporting the Needs of Older Adults. Health Professions Press, Baltimore, Maryland.

Fish, J. 201 2. Social Work and Lesbian, Gay, Bisexual and Trans People: Making a Difference. Policy Press, Bristol, UK.

Fredriksen-Goldsen, K. I. and Muraco, A. 2010. Aging and sexual orientation: a 25-year literature review. Research on Aging, 32, 3, 372-413.

Harrison, J. 20o6. Coming out ready or not! Gay, lesbian, bisexual, transgender and intersex ageing and aged care in Australia: reflections, contemporary developments and the road ahead. Gay and Lesbian Issues in Psychology Review, 2, 2, 44-53.

Health and Care Development Ltd 2006. Lifting the Lid on Sexuality and Ageing: A Research Project into the Needs, Wants, Fears and Aspirations of Older Lesbians and Gay Men. Help and Care, Bournemouth, UK.

Healy, K. 2005. Social Work Theories in Context-Creating Frameworks for Practice. Palgrave Macmillan, Basingstoke, UK.

Heaphy, B. and Yip, A. 2003. Uneven possibilities: understanding non-heterosexual ageing and the implication of social change. Sociological Research Online, 8, 4, 1-19.

Heaphy, B., Yip, A. and Thompson, D. 2004. Ageing in a non-heterosexual context. Ageing E्F Society, 24, 6, 881-902.

Hughes, M. 2009. Lesbian and gay people's concerns about ageing and accessing services. Australian Social Work, 62, 2, 186-201.

Jackson, N. C., Johnson, M.J. and Roberts, R. 2008. The potential impact of discrimination fears of older gays, lesbians, bisexuals and transgender individuals living in small- to moderate-sized cities on long-term health care. Journal of Homosexuality, 54, 3, 325-39. 
Johnson, M. J., Jackson, N. C., Arnette, J. K. and Koffman, S. D. 2005. Gay and lesbian perceptions of discrimination in retirement care facilities. Journal of Homosexuality, 49, 2, 83-102.

Knockel, K.A., Quam, J.K. and Corghan, C.F. 2011. Are old lesbian and gay people well served? Understanding the perceptions, preparation, and experiences of aging services providers. Journal of Applied Gerontology, 3o, 3, 370-89.

Lloyd, L. 2006. A caring profession? The ethics of care and social work with older people. British Journal of Social Work, 36, 7, $1171-85$.

Lyons, A., Pitts, M. and Grierson, J. 2013. Growing old as a gay man: psychosocial wellbeing of a sexual minority. Research on Ageing, 35, 3, 275-95.

McPhail, B. A. 2004. Questioning gender and sexuality binaries: what queer theorists, transgendered individuals, and sex researchers can teach social work. Journal of Gay and Lesbian Social Services, 17, 1, 3-21.

Nolan, M. R., Davies, S., Brown, J., Keady, J. and Nolan, J. 2004. Beyond 'personcentred' care: a new vision for gerontological nursing. International Journal of Older People Nursing in Association with Journal of Clinical Nursing, 13, 3a, 45-53.

Phillips, J. and Marks, G. 20o6. Coming out, coming in: how do dominant discourses around aged care facilities take into account the identities and needs of ageing lesbians? Gay and Lesbian Issues and Psychology Review, 2, 2, 67-77.

Price, E. 2011. LGBT sexualities in social care research. Methods Review 2. School for Social Care Research. Available online at https://www.lse.ac.uk/LSEHealthAndSocialCare/pdf/SSCR_Methods_Review_2.pdf [Accessed 1 December 2013].

Pugh, S. 2012 . Care anticipated: older lesbians and gay men consider their future needs. In Ward, R., Rivers, I. and Sutherland, M. (eds), Lesbian, Gay, Bisexual and Transgender Ageing: Biographical Approaches for Inclusive Care and Support. Jessica Kingsley Publishers, London, 39-50.

Richardson, D. 1996. Theorising Heterosexuality-Telling it Straight. Open University Press, Buckingham, UK.

Savin-Williams, R. C. 2005. The New Gay Teenager. Harvard University Press, Cambridge, Massachusetts.

Sevenhuijsen, S. 2000. Caring in the third way: the relation between obligation, responsibility and care in Third Way discourse. Critical Social Policy, 2o, 1, 5-37.

Stein, G. L., Beckerman, N. L. and Sherman, P. A. 2010. Lesbian and gay elders and long-term care: identifying the unique psychosocial perspectives and challenges. Journal of Gerontological Social Work, 53, 5, 421-35.

Stonewall 2011. Lesbian, Gay and Bisexual People in Later Life. Available online at http://www.stonewall.org.uk/documents/lgb_in_later_life_final.pdf [Accessed 27 August 2013].

Tolley, C. and Ranzijn, R. 20o6. Heteronormativity amongst staff of residential aged care facilities. Gay and Lesbian Issues and Psychology Review, 2, 2, 78-86.

Tronto, J. C. 1993. Moral Boundaries: A Political Argument for an Ethic of Care. Routledge, New York.

Twigg, J. 200o. Carework as a form of bodywork. Ageing $\mathcal{E}$ Society, 2o, 4, 389-41 1.

Warner, M. 1993. Introduction. In Warner, M. (ed.), Fear of a Queer Planet: Queer Politics and Social Theory. University of Minnesota Press, Minneapolis, Minnesota, vii-xxxi.

Welsh Government 2013. Strategy for Older People in Wales 2OI3-2023. Available online at http://wales.gov.uk/docs/dhss/publications/130521 olderpeoplestrategyen. pdf [Accessed 25 August 2013].

White, J. A. and Tronto, J. C. 2004. Political practices of care: needs and rights. Ratio Juris, 17, 4, 425-53. 
Windle, G. and Burholt, V. 20o6. The Sexual Health of Older People. Welsh Assembly Government, Cardiff, UK.

World Health Organisation 2013. Health Topics-Sexual Health. Available online at http://www.who.int/topics/sexual_health/en/ [Accessed 25 August 2013].

Yep, G. A. 2002. From homophobia and heterosexism to heteronormativity: toward the development of a model of queer interventions in the university classroom. Journal of Lesbian Studies, 6, 3/4, 163-76.

Accepted 8 September 2 oI4; first published online I4 October 2014

Address for correspondence:

Paul Willis, Centre for Innovative Ageing,

Vivian Tower Level 3 , College of Human and Health Sciences,

Swansea University, Swansea SA2 8PP, UK.

E-mail: P.B.Willis@swansea.ac.uk. 